\title{
Gel Chromatographic Characterization of Immunoreactive Adrenocorticotropin in Patients with ACTH Hypersecretion *, **
}

\author{
M. Reincke, B. Allolio, U. Deuß and W. Winkelmann \\ Medizinische Universitätsklinik II, Köln-Merheim (Prof. Dr. Werner Kaufmann)
}

Summary. We investigated the molecular size of circulating immunoreactive ACTH by gel chromatography in patients with ACTH hypersecretion due to various disorders of the hypothalamic-pituitary-adrenal axis. 4 patients with Addison's disease, 2 with Nelson's syndrome, 4 with Cushing's disease, 6 with the ectopic ACTH syndrome (2 bronchial carcinoma, 1 medullary carcinoma, 1 metastatic islett cell carcinoma, 1 benign bronchial carcinoid and 1 patient with occult ectopic Cushing's syndrome) and 1 patient with hypersecretion of ACTH from a clinically nonfunctioning pituitary adenoma were studied. Analysis of the molecular size of immunoreactive ACTH was performed by gel chromatography on a Sephadex G-75 column (superfine, $100 \times 1.5 \mathrm{~cm}$ ) equilibrated with $1 \%$ formic acid. $2 \mathrm{ml}$ fractions were collected and evaporated to dryness. The ACTH content of the recovered samples was determined by RIA. In Addison's disease, Nelson's syndrome and Cushing's disease the plasma showed a single peak of ACTH immunoreactivity at the expected position of 1-39 ACTH. In the ectopic ACTH syndrome the plasma of 4 patients revealed at chromatography at least one other peak eluting between the void volume and 1-39 ACTH suggestive of a high molecular weight form of ACTH whereas plasma of 2 patients showed only a single ACTH peak at the position of labeled 1-39 ACTH. The patient with a clinically non-functioning pituitary adenoma revealed a gel filtration pattern similar to the patients with ectopic ACTH syndrom and se-

\footnotetext{
* Supported by the Landesamt für Forschung Nordrheinwestfalen

** Dedicated to Professor Dr. W. Kaufmann on the occasion of his 65 th birthday

Abbreviations: $\mathrm{ACTH}=$ adrenocorticotropin; $\mathrm{MSH}=$ melanocyte stimulating hormone $\mathrm{I}=$ iodine POMC $=$ proopiomelanocortin; RIA = radioimmunoassay
}

cretion of high molecular weight ACTH. We conclude that secretion of high molecular weight forms of $\mathrm{ACTH}$ is not a unique feature of the ectopic ACTH syndrome. It may therefore not serve as a marker of the ectopic Cushing's syndrome in the differential diagnosis of the ACTH dependent Cushing's syndrome. Vice versa, lack of high molecular weight ACTH does not exclude an ectopic source of ACTH secretion as cause of Cushing's syndrome.

Key words: ACTH - Cushing's syndrome - proopiomelanocortin - Nelson's syndrome - Addison's disease

It has been established that the pituitary peptides $\mathrm{ACTH}, \beta$-lipotropin and $\beta$-endorphin originate from a common precursor, proopiomelanocortin (POMC) [7, 8]. Abnormalities in the processing of POMC have been reported in the ectopic ACTH syndrome resulting in the secretion of various high molecular weight forms of ACTH [11, 15]. Since differentiation of patients with ectopic Cushing's syndrome from pituitary dependent Cushing's syndrome (Cushing's disease) may be difficult in some cases it has been suggested that variations in the secretion pattern of ACTH may have diagnostic significance [5].

Therefore, we investigated the diagnostic value of gel chromatography of plasma ACTH in various disorders of the hypothalamic-pituitary-adrenal axis.

\section{Patients and Methods}

The plasma of 4 patients with Addison's disease, 2 patients with Nelson's syndrome, 4 patients with 
Table 1. Clinical characteristics of patients with ACTH-hypersecretion

\begin{tabular}{|c|c|c|c|c|c|}
\hline Pat. & $\begin{array}{l}\text { Age } \\
\text { (years) }\end{array}$ & Sex & Diagnosis & Treatment & $\begin{array}{l}\text { Plasma-ACTH Concentration } \\
(\mathrm{pg} / \mathrm{ml})\end{array}$ \\
\hline 1. & 44 & $\mathrm{~F}$ & Addison's disease & steroid replacement therapy & 1800 \\
\hline 2. & 56 & $\mathrm{~F}$ & Addison's disease & steroid replacement therapy & 880 \\
\hline 3. & 22 & $F$ & Addison's disease & steroid replacement therapy & 680 \\
\hline 4. & 35 & $\mathrm{M}$ & Addison's disease & steroid replacement therapy & 249 \\
\hline 5. & 52 & $\mathrm{M}$ & Cushing's disease (mic.) & bilateral adrenalectomy & 396 \\
\hline 6. & 31 & $F$ & Cushing's disease (mic.) & - & 78 \\
\hline 7. & 59 & $\mathrm{~F}$ & Cushing's disease (mic.) & bilateral adrenalectomy & 800 \\
\hline 8. & 44 & $\mathrm{~F}$ & Cushing's disease (mac.) & transsphenoidal neurosurgery & 696 \\
\hline 9. & 42 & $\mathrm{~F}$ & Nelson's syndrome & bilateral adrenalectomy, irradiation & 12700 \\
\hline 10. & 56 & $\mathrm{~F}$ & Nelson's syndrome & bilateral adrenalectomy, irradiation & 5287 \\
\hline 11. & 66 & M & bronchial carcinoma & adrenostatic therapy & 3100 \\
\hline 12. & 60 & $\mathrm{M}$ & bronchial carcinoma & adrenostatic therapy & 1200 \\
\hline 13. & 42 & $\mathrm{M}$ & met. islet carcinoma & adrenostatic therapy & 605 \\
\hline 14. & 45 & $\mathrm{~F}$ & met. medullary carcin. & adrenostatic therapy & 438 \\
\hline 15. & 29 & $F$ & bronchial carcinoid & bilateral adrenalectomy & 545 \\
\hline 16. & 37 & $\mathrm{~F}$ & occult ectopic C. sy. & adrenostatic therapy & 300 \\
\hline 17. & 46 & $\mathrm{M}$ & 'silent' pituit. aden. & transsphenoidal neurosurgery & 380 \\
\hline
\end{tabular}

$\mathrm{F}=$ female $; \mathrm{M}=$ male $;$ mic. $=$ microadenoma $;$ mac. $=$ macroadenoma $; \mathrm{C} . \mathrm{sy} .=$ Cushing's syndrome

pituitary dependent Cushing's disease ( 3 micro-, 1 macroadenoma), 6 patients with the ectopic ACTH-dependent Cushing's syndrome and 1 patient with a clinically silent corticotropic pituitary adenoma was studied.

Clinical details of the patients are summerized in Table 1. All patients with Nelson's syndrome had increased skin pigmentation and a surgically proven corticotropic macroadenoma following bilateral adrenalectomy for pituitary dependent Cushing's disease. In patients with Cushing's disease the pituitary source of ACTH hypersecretion was confirmed by neurosurgery or by selective catheterization of the sinus petrosus inferior [3]. Of the patients with the ectopic Cushing's syndrome 2 had small cell bronchial carcinoma, 1 had an islet cell carcinoma with diffuse metastases to the liver, 1 patient had metastatic medullary carcinoma, 1 patient had a benign bronchial carcinoid and 1 patient suffered from the occult ectopic Cushing's syndrome [4]. The cases of the latter 2 patients have been reported in detail elsewhere [13]. The patient with a corticotropic macroadenoma confirmed by transsphenoidal neurosurgery showed elevated plasma ACTH levels without evidence of Cushing's disease. His findings have been described previously [12] and were suggestive of a pituitary tumor secreting biologically inactive ACTH.

Analysis of the molecular size of circulating immunoreactive ACTH was performed by gel chromatography, as described by Ratter et al. [11] in detail. Briefly, a column of Sephadex G-75 (superfine; $100 \times 1.5 \mathrm{~cm}$ ) equilibrated with $1 \%$ formic acid was used. $2 \mathrm{ml}$ preacidified plasma samples were applied to the column and pumped downwards at a flow rate of $2,5 \mathrm{ml} /$ hour. $2 \mathrm{ml}$ samples were collected and evaporated to dryness. The fractions were reconstituted with a sodium phosphat buffer and set up for determination of immunoreactive ACTH. The ACTH content was measured in triplicate by radioimmunoassay [1]. The antibody cross-reacted completely with ACTH-(1-24), human(h) ACTH-(1-39), and ACTH-(11-24), and did not react with ACTH-(1-10), hACTH-(27-39), $\beta$ hMSH, or $\alpha$ hMSH. The minimal detectable concentration of immunoreactive ACTH was $5 \mathrm{pg} / \mathrm{ml}$.

The colum was calibrated with dextran blue (void volume), $\mathrm{I}^{125}$-prolactin and $\mathrm{I}^{125}-\mathrm{ACTH}$ (1-39). The recovery of nanogram amounts of 1-39 ACTH added to acid-treated plasma containing no immunoreactive $\mathrm{ACTH}$ and applied to the column was over $75 \%$.

\section{Results}

In patients with Addison's disease gel chromatography revealed a single peak of immunoreactive ACTH eluting at the position of labeled 1-39 ACTH. No other distinct peaks were seen in these patients.

Patients with ACTH hypersecretion due to pituitary dependent Cushing's disease and Nelson's syndrome also demonstrated a single peak of im- 


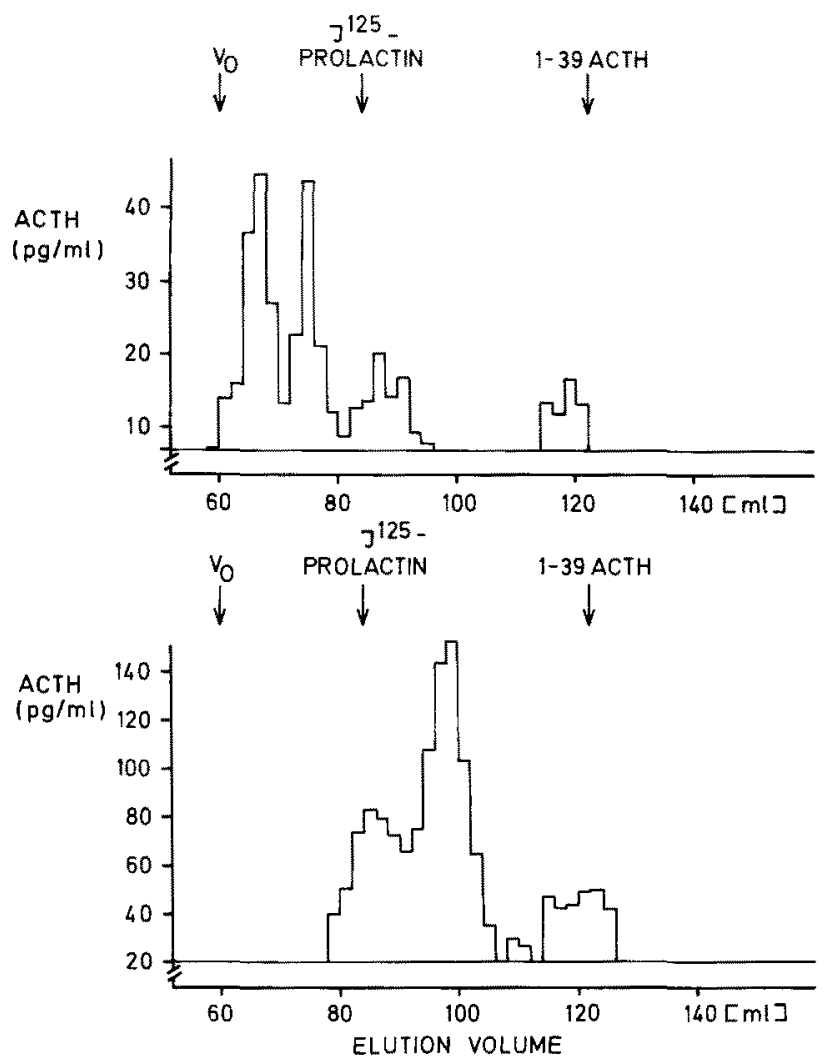

Fig. 1. Gel filtration pattern of plasma ACTH obtained from 2 patients with the ectopic ACTH syndrome due to a bronchial carcinoma

munoreactive ACTH at the position of $\mathrm{I}^{125}-1-39$ ACTH tracer representing ACTH with a molecular weight of 4500 daltons. No other significant peaks of ACTH immunoreactivity were detected.

In patients with the ectopic ACTH syndrome gel chromatography of plasma samples showed three different pattern.

In patients with small cell carcinoma of the lung gel filtration revealed a small ACTH peak at the expected position of 1-39 ACTH together with several peaks of $\mathrm{ACTH}$ immunoreactivity eluting between the void volume and 1-39 ACTH, accounting for most of the ACTH detected (Fig. 1). These peaks were suggestive of multiple high molecular weight forms of ACTH indicating abnormal cleavage of the POMC precusor resulting in the release of peptides of different molecular weight by the tumor cells.

In 2 patients with the ectopic $\mathrm{ACTH}$ syndrome (metastatic carcinoid and medullary carcinoma), in addition to a peak representing 1-39 ACTH, one other peak eluted midways between the void volume and 1-39 ACTH, eluting in the same position as $\mathrm{I}^{125}$-prolactin (molecular weight 22000 daltons) (Fig. 2).

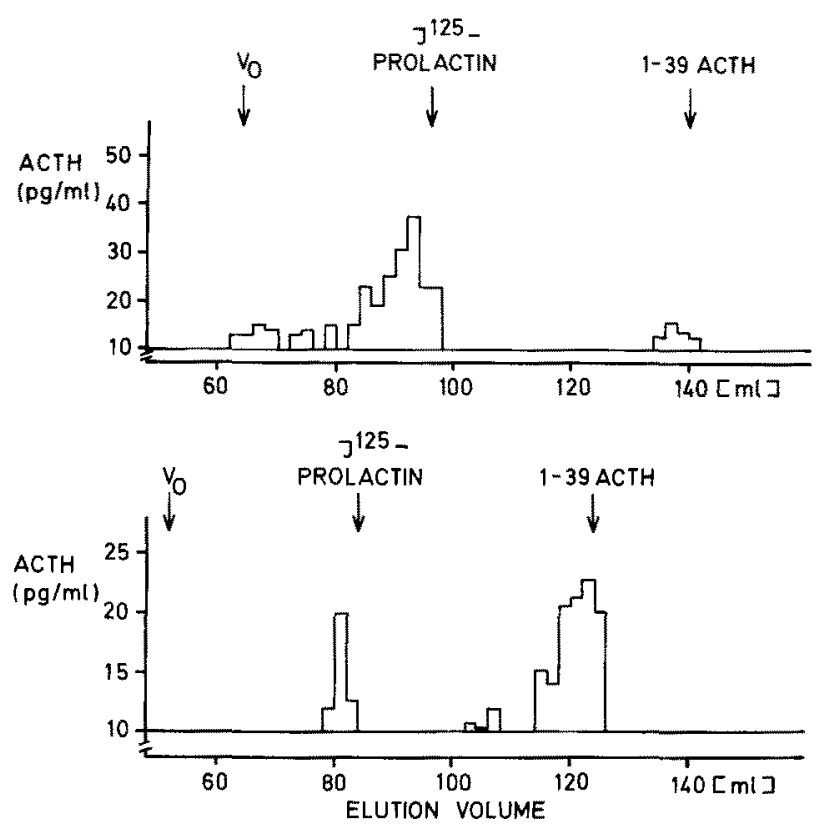

Fig. 2. Gel filtration pattern of plasma ACTH from a patient with a metastatic islet cell carcinoma (above) and from a patient with a metastatic medullary carcinoma (bottom)

In contrast, plasma samples of the patient with occult ectopic Cushing's syndrome and of the patient with a benign bronchial carcinoid, respectively, revealed a single peak of immunoreactive ACTH at the position of 1-39 ACTH without other distinct ACTH peaks.

The plasma of the patient with a large aggressive pituitary tumor and elevated plasma ACTH concentrations without signs of Cushing's disease showed a chromatographic profile of ACTH immunoreactivity similar to patients with ectopic ACTH syndrome: a very small peak appeared at the position of 1-39 ACTH; the second, predominant peak, eluting midway between the void volume and 1-39 ACTH, with a molecular weight of approximately 22000 , indicated the presence of a large molecular weight form of $\mathrm{ACTH}$, apparently without biological activity (Fig. 3).

\section{Discussion}

In the past decade it has been established that $\mathrm{ACTH}, \beta$-lipotropin and $\beta$-endorphin originate from a common precursor known as proopiomelanocortin (POMC) [8]. Production of ACTH and related peptides involves an intermediate step wherein the C-terminal $\beta$-lipotropin is cleaved first followed by the cleavage of ACTH [7]. Peptides derived from POMC are secreted concomitantly from the pituitary gland in response to diverse 


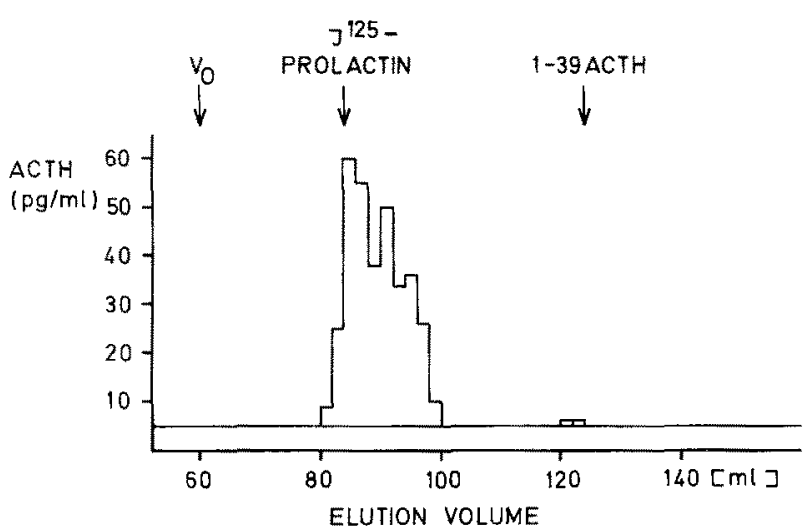

Fig. 3. Gel chromatographic characterization of plasma ACTH obtained from a patient with a corticotropic pituitary adenoma and elevated plasma ACTH levels without evidence of Cushing's syndrome

stimuli. In normal subjects the only circulating form of ACTH immunoreactivity is $1-39 \mathrm{ACTH}$ [11]. In patients with disorders of the hypothalamic-pituitary-adrenal axis abnormalities of the processing of POMC have been observed resulting in the secretion of various large molecular weight forms of ACTH $[5,6,7,11,12,15,16]$. In patients with Addison's disease, Nelson's syndrome and Cushing's disease we found only a single peak of immunoreactive $\mathrm{ACTH}$ eluting at the same position as labeled 1-39 ACTH. These results are in accordance to the investigation of Ratter et al. [11]. In contrast, Thoren et al. [14] observed a high molecular weight form of ACTH in normal subjects and patients with Nelson's syndrome by gel filtration which eluted in the void volume. However, these findings may be explained by a non-specific binding of the antibody to non-ACTH related peptides.

High molecular weight forms of ACTH were first found in plasma of patients with the ectopic ACTH syndrome [15]. Consecutively, it has been suggested that variations in the secretion pattern of ACTH may have diagnostic significance in the $\mathrm{ACTH}$ dependent Cushing's syndrome [5]. Incomplete or aberrant processing of POMC with secretion of 'big' ACTH appeared to be a characteristic feature of the ectopic Cushing's syndrome. Ratter et al. [11] demonstrated at least one other peak of $\mathrm{ACTH}$ immunoreactivity suggestive of a high molecular weight form of ACTH in 20 patients with the ectopic ACTH syndrome.

In some cases of the ectopic ACTH syndrome differentiation from pituitary dependent Cushing's disease may be difficult. Especially small or even occult ACTH secreting 'nonendocrine' tumors frequently mimic biochemical characteristics of Cush- ing's disease [4]. Therefore, 'big' ACTH secretion by these tumors would be a useful marker of ectopic ACTH secretion and would facilitate the differential diagnosis of ACTH dependent Cushing's syndrome. However, our results demonstrated that high molecular weight ACTH is not present in all cases of ectopic Cushing's syndrome. Seemingly secretion of 'big' ACTH is a characteristic feature of malignant ACTH producing tumors (i.e. bronchial carcinomas) reflecting dedifferentiation of tumor cells. In contrast, 'big' ACTH is lacking in plasma of our patients with the ectopic ACTH syndrome due to small benign or occult tumors. Therefore, lack of 'big' ACTH favours pituitary dependent Cushing's disease, but it does not exclude ectopic ACTH secretion.

Interestingly patients with Cushing's disease due to large aggressive pituitary tumors have been described with secretion of high molecular weight forms of ACTH [5, 6]. We observed a patient with hypersecretion of ACTH from an aggressive corticotropic pituitary tumor who did not have hypercortisolism. Gel chromatography of the patients plasma showed a pattern typical for the ectopic ACTH syndrome: $95 \%$ of the ACTH detected eluted midways between the void volume and 1-39 ACTH. Since hypercortisolism was ruled out this high molecular weight form of ACTH had no or little bioactivity. These findings demonstrate that the secretion of 'big' $\mathrm{ACTH}$ is not a unique feature of the ectopic ACTH syndrome. It may also be present in rare cases of aggressive corticotropic adenomas or carcinomas of the pituitary.

It has been suggested that high molecular weight forms of ACTH are implicated in the mechanism underlying the appearance of hypokaliaemia typical for patients with the ectopic Cushing's syndrome. In vitro there has been evidence of a potentiation of the ACTH induced steroidogenesis by 'big' ACTH in cultered adrenocortical cells [10]. However, Chatelain et al. [2] reported that 'big' ACTH did not modify the corticosteroidogenic activity of $1-39 \mathrm{ACTH}$ in perfused adrenal glands of the rat. Indirectly our results also are not in favour of this hypothesis since in our patients with ectopic ACTH syndrome without secretion of 'big' ACTH (Pat. 15 and 16) hypokaliaemia or low normal potassium concentrations were observed. Therefore, hypokaliaemia in ectopic Cushing's syndrome may be more a result of greatly elevated plasma levels of 1-39 ACTH which in turn stimulate adrenal steroidogenesis.

In conclusion, while the presence of high molecular weight ACTH favours the diagnosis of ectopic Cushing's syndrome, this is not a specific 
feature of it. On the other hand, the absence of 'big' ACTH in plasma will not rule out Cushing's syndrome due to a benign or an occult ectopic ACTH source.

Acknowledgments: We are indebted to Miss D. Vollmar, Mrs H. Hofmann, Miss M. Krietemeyer and Mrs. G. RoBbach for skillful technical assistance.

\section{References}

1. Allolio B, Hipp FX, Winkelmann W (1981) The effect of meclastine, an antihistamine, on plasma ACTH in adrenal insufficiency. Acta Endocrinol (Copenh) 97:98-102

2. Chatelain A, Cheong H-S (1987) The biological activity of different molecular forms of ACTH on corticosterone production by perfused foetal rat adrenal glands in vitro. Acta Endocrinol (Copenh) 116:179-185

3. Doppmann JL, Oldfield E, Krudy AG, Chrousos GP, Schulte HM, Schaaf M, Loriaux DL (1984) Petrosal sinus sampling for Cushing's syndrome: anatomical and technical considerations. Radiology 150:99-103

4. Findling JW, Tyrrell JB (1986) Occult ectopic secretion of corticotropin. Arch Intern Med 146:929-933

5. Fuller PJ, Alan TWL, Barlow JW, White EL, Khalid BAK, Copolov DL, Lolait S, Funder JW, Stockigt JR (1984) A pituitary tumor producing high molecular weight ACTHrelated peptides: clinical and cell cultures studies. J Clin Endocrinol Metab 58:134-142

6. Hale AC, Millar JGB, Ratter SJ, Pickard JD, Doniach I, Rees LH (1985) A case of pituitary dependent Cushing's disease with clinical and biochemical features of the ectopic ACTH syndrome. Clin Endocrinol (Oxf) 22:479-488

7. Imura H (1985) ACTH and related peptides: molecular biology, biochemestry and regulation of secretion. Clin Endocrinol Metab 14:845-866

8. Mains RE, Eipper BA, Ling N (1977) Common precursor to corticotropins and endorphins. Proc Nat Acad Sciences $74: 3014-3018$
9. Nakao K, Oki S, Tanaka I, Nakai Y, Imura H (1980) Concommitant secretion of -MSH with ACTH and $\beta$-endorphin in humans. J Clin Endocrinol Metab 51:1205-1209

10. Pedersen RC, Brownie AC (1980) Adrenocrotical response to ACTH is potentiated by part of the amino terminal region of pro-corticotropin-endorphin. Proc Nat Acad Sciences $77: 2239-2241$

11. Ratter SJ, Lowry PJ, Besser GM, Rees LH (1980) Chromatographic characterization of ACTH in human plasma. $\mathrm{J}$ Endocrinol 85:359-369

12. Reincke M, Allolio B, Saeger W, Kaulen D, Winkelmann W (1987) A pituitary adenoma secreting high molecular weight ACTH without evidence of Cushing's syndrome. J Clin Endocrinol Metab 65:1296-1300

13. Reincke M, Allolio B, Jaursch-Hancke C, Kaulen D, Saeger W, Leonhard U, Günther RW, Winkelmann W (1988) Diagnostische Probleme beim ektopen Cushing-Syndrom. Med Klin 17:559-564

14. Thoren M, Ajne M, Hall K (1981) Plasma pattern of irACTH in normal man and in patients with Nelson's syndrome. Acta Endocrinol (Copenh) 96:15-23

15. Yalow RS, Berson SA (1971) Size heterogeneity of ir-hACTH in plasma and extracts of pituitary gland and ACTH-producing thymoma. Biochem Biophys Res Comm 43:439-445

16. Yamada $\mathrm{Y}$, Ito $\mathrm{S}$, Miyashita $\mathrm{M}$, Kaneko $\mathrm{K}$, Watanabe $\mathrm{T}$, Shibata A, Sasaki H, Tsutsui K, Kayamori R (1978) Clinical studies of 'Big'-ACTH: its physicochemical characteristics. Acta Endocrinol 89:221-231

Received: June 21, 1989

Returned for revision: July 11, 1989

Accepted: July 28, 1989

Dr. Martin Reincke

Med. Univ. Klinik II,

Krankenhaus Merheim,

Ostmerheimer Str. 200

D-5000 Köln 91 